\title{
Bases para o ensino/aprendizagem de projeto no design de moda: conectando diretrizes didáticas e estratégias metodológicas
}

Basis for project teaching/learning in fashion design: conecting didactic directions and methodological strategies

\section{Maria Celeste de Fátima Sanches}

Mestre; Faculdade de Arquitetura e Urbanismo da Universidade de São Paulo e Universitat Politècnica de València tsanches@sercomtel.com.br

Thassiana de Almeida Miotto

Mestre; Universidade Estadual de Londrina thassi@hotmail.com

\section{Bernabé Hernandis Ortuño}

Phd; Universitat Politècnica de València bhernandis@degi.upv.es

\section{Sérgio Regis Moreira Martins}




\title{
Bases para o ensino/aprendizagem de projeto no design de moda: conectando diretrizes didáticas e estratégias metodológicas
}

\author{
Basis for project teaching/learning in fashion design: conecting didactic directions and \\ methodological strategies
}

Maria Celeste de Fátima Sanches, Thassiana de Almeida Miotto, Bernabé Hernandis Ortuño, Sérgio Regis Moreira Martins.

\section{Resumo}

$\mathrm{O}$ artigo apresenta resultados parciais de uma pesquisa de doutoramento, desenvolvida na parceria entre FAU- USP, Universitat Politècnica de València e Universidade Estadual de Londrina, a qual tem o propósito de estudar o instrumental metodológico de design de moda, abordando ferramentas que se destinam a facilitar a sintaxe formal de artefatos vestíveis, no âmbito do ensino de projeto. Nesta direção, esta explanação relata um recorte da pesquisa exploratória. Conciliando levantamento bibliográfico e análise documental de práticas acadêmicas, define os construtos norteadores da abordagem didática para a utilização das ferramentas metodológicas do design. Os resultados reforçam a hipótese de que o bom raciocínio projetual é construído sobre a plataforma da "aprendizagem significativa", dos modelos sistêmicos de gestão do conhecimento e dos métodos de síntese.

Palavras- chave: design de moda, projeto, metodologia.

\begin{abstract}
The present article presents partial results of a Ph. D. research, developed through a partnership among FAU-USP, Universitàt Politecnica de València and UEL, which purpose is the study of a fashion design methodological instrumental bringing up tools that are destined to facilitate the formal syntax of wearable artifacts, within the project of teaching. In this way, this explanation reports a snip of the exploratory research. Arranging the academic practice bibliographic closing and document analysis, it defines the construct guiding of a didactic approach to the use of methodological tools of design. The results reinforce the hypothesis that a good project reasoning is built on the platform of "significant learning", of knowledge management systemic models and of synthesis methods.
\end{abstract}

Keywords: fashion design, project, methodology 


\section{Introdução}

Nas esferas acadêmicas, parece ser consenso que a formação de um designer visa, principalmente, o desenvolvimento da capacidade projetiva deste sujeito. Assim, os esforços pedagógicos se concentram na premissa de que o cerne desta atividade profissional é "projetar" as interfaces (tangíveis ou intangíveis) que mediam a integração humana com o contexto sociocultural. Entretanto, os termos projetar e projeto costumam gerar uma diversidade de interpretações, conforme o campo em que se aplica, podendo referir-se tanto à ideia do processo, como do produto gerado ao final do mesmo. Por isso, demarcaremos que o foco desta explanação é examinar processos. Interessa-nos a investigação do trajeto percorrido e as condutas usadas para sistematizálo, com o propósito de estudar abordagens pedagógicas que facilitem o ensino/aprendizagem de projeto no design de moda.

Neste sentido, Sanches (2010), destaca que a formação acadêmica dos designers da contemporaneidade deve solidificar a capacidade de síntese integradora dos estudantes, ou seja, a competência para interpretar, gerenciar e conectar variáveis, extraindo dessas interações a essência dos elementos envolvidos. Em vista disso, muitos docentes das graduações em design têm se dedicado à construção de conhecimento de forma mais autônoma e participativa, no que concerne ao papel do aluno, bem como repensam as estratégias pedagógicas para efetivar essa interação. Igualmente, a presente reflexão examina os preceitos metodológicos do design sob esse enfoque sistêmico, promovendo algumas conexões entre princípios de gestão projetual e posturas didáticas para exercitálos.

Sobre esta plataforma, relatamos o transcurso de uma investigação exploratória, realizada para uma pesquisa de doutoramento desenvolvida na parceria entre FAUUSP, Universitat Politècnica de València (UPV) e Universidade Estadual de Londrina (UEL). A pesquisa visa investigar o instrumental metodológico do design de moda, no âmbito do ensino de projeto. Destacamos que, como o universo pedagógico estudado se concentra no ambiente acadêmico da UEL, onde a expressão utilizada para referir-se ao campo da gestão do projeto de artefatos de vestuário de moda foi convencionada como "design de moda", adotamos a mesma nomenclatura para as nossas reflexões. 
Neste contexto, a pesquisa exploratória concilia levantamento bibliográfico e análise documental, indicando diretrizes para a abordagem didática e a utilização de ferramentas metodológicas projetuais no domínio do design de moda. Os resultados encontrados reforçam a hipótese de que o bom raciocínio projetual é construído sobre a plataforma da "aprendizagem significativa", dos modelos sistêmicos de gestão do conhecimento e dos métodos de síntese. Desta forma, construímos parte do alicerce da supracitada pesquisa de doutoramento e, principalmente, avançamos na busca por melhores práticas educacionais para o desenvolvimento da capacidade de integrar variáveis projetuais na concepção de interfaces vestíveis.

\section{Abordagem metodológica}

Como já citado, o artigo relata um recorte da pesquisa exploratória de uma pesquisa de doutoramento que se destina a investigar o instrumental metodológico do design de moda, no âmbito do ensino de projeto, abordando ferramentas que se destinam a facilitar a sintaxe formal de produtos de vestuário de moda. A caminho desse propósito foi fundamental definir uma abordagem didática para a aplicação de metodologias do design no campo da moda. Para tanto, essa parte da pesquisa centrouse na identificação das principais aptidões a serem desenvolvidas no ensino/aprendizagem do projeto de design de moda, delineando um enfoque didático apropriado. Assim, relatamos neste tópico os procedimentos que conduziram este estudo específico.

A investigação integrou revisão de literatura e análise documental. Esclarecemos que a abordagem metodológica foi qualitativa, uma vez que a pesquisa de doutoramento já contava com as sínteses de registros de observação participante em aula, os quais embasaram a escolha das estratégias do presente estudo e auxiliaram a delimitação e a objetividade das análises.

Para alavancar a construção do alicerce teórico da etapa de pesquisa aqui tratada, definimos alguns questionamentos. - Que elementos costumam influenciar a delimitação de situações projetuais no design de moda? - Que aptidões são necessárias ao designer de moda sob o enfoque sistêmico? - Que abordagens educacionais se integram melhor à construção do raciocíno projetual no âmbito acadêmico estudado? 
Sob estas diretrizes, o estudo examinou bases teóricas sobre a conduta projetual em design, o pensamento sistêmico e as teorias da pedagogia. Assim, foi possível definir parâmetros para averiguar as práticas projetuais realizadas no Curso de Design de Moda da UEL, onde atuamos como docentes na disciplina de Metodologia do Projeto e participamos efetivamente da construção do projeto pedagógico do curso atual. Para maior esclarecimento, a seguir apresentamos a organização dos procedimentos efetuados.

PRIMEIRA PARTE- A) Revisão de literatura para compreensão dos pontos cruciais do trajeto projetual no design de moda. B) Delimitação dos agentes influenciadores e fluxo de informação no projeto de design de moda. C) Definição de indicadores para classificar os registros de práticas projetuais acadêmicas no design de moda. D) Análise documental dos registros acadêmicos (fichas-síntese) - enumeração dos critérios e restrições mais utilizados nas sínteses de delimitadores projetuais no design de moda. E) Identificação dos níveis de experiência que o vestuário de moda estabelece na relação de uso. F) Síntese das categorias de variáveis fundamentais que influenciam o projeto de design de moda.

SEGUNDA PARTE- A) Acoplamento das bases teóricas e resultados da primeira parte, integrando as teorias sobre o pensamento projetual B) Organização do quadro de conexões entre a gestão de informações, o foco das ações e as capacidades envolvidas no pensamento projetual de design de moda, a partir da visão panorâmica do fluxo de variáveis identificadas na primeira parte da pesquisa. C) Análise comparativa identificação das principais aptidões a serem exercitadas e das abordagens pedagógicas que favorecem a construção do raciocínio projetual.

Esclarecemos que o estudo documental utilizou registros de práticas projetuais efetuados pelos próprios estudantes. Com base nos indicadores apontados pelas bases teóricas (funcionalidade/usabilidade e prazer), analisamos o tópico "necessidades a serem atendidas" nas fichas-síntese, documento utilizado regulamente no curso em questão. Os registros foram classificados, promovendo a identificação dos atributos mais apontados como parâmetros importantes no sistema corpo-vestuário-ambiente e evidenciando tópicos comuns na busca/gestão de informações em projetos de design de moda. 


\section{Bases Teóricas}

\subsection{Projetar Moda}

A premissa de utilizar algum tipo de metodologia para organizar o raciocínio projetual já é largamente aceita nas escolas de design, mesmo que no âmbito dos cursos de moda esse tema ainda se mostre incipiente em investigações específicas. Por isso, pretendemos examinar as abordagens atuais sobre metodologias de projeto em design, com o propósito de edificar bases norteadoras para a formação do raciocínio projetual entre os alunos do Curso de Design de Moda da Universidade Estadual de Londrina (UEL).

No entanto, concordando com Lawson (2011), devemos iniciar essa busca com a prudência de ressaltar que esquadrinhar definições concisas para o vocábulo "projetar", pode não satisfazer a complexidade do tema, uma vez que o ato é marcado pela necessidade de adotar pensamentos e conhecimentos de natureza muito diversificada. Por conseguinte, decidimos não propor uma definição para o termo, apenas demarcar o foco na análise do processo que ocorre entre a demanda (problema) e a proposta para atende-la (solução). Neste sentido, pontuamos as ações de pensamento envolvidas no trajeto e sintetizamos diretrizes para sua sistematização.

Antes de indicar os pontos fundamentais do projeto de design de moda especificamente, é importante resgatar algumas noções gerais sobre o processo de design na atualidade. Neste sentido, Dias e Gontijo (2006) destacam que, em um contexto multifacetado como o atual, é necessário analisar os problemas de design com lentes múltiplas, levando em conta o maior número possível de pontos de vista e de perspectivas de análise. Na mesma perspectiva, Sanches (2011) argumenta que a conduta de um projeto de design é, em essência, um processo vivo e dinâmico, já que os parâmetros da realidade que o aloja podem ser flutuantes. A partir das ponderações anteriores, inferimos dois fatores importantes envolvidos no pensamento projetual: a incerteza e a diversidade de possibilidades.

Estes fatores estão sempre presentes no ato projetual, uma vez que projetar presume a condição de antever o futuro, o planejamento de algo que ainda não se conhece, ou que não é plenamente conhecido. Assim, entendemos que o caminho trilhado entre o problema (pergunta) e a solução (resposta) de projeto não é previamente determinado. No trajeto, as decisões se conectam umas às outras a partir de uma rede 
dinâmica que vai assimilando novas informações e se modificando até delinear uma trajetória viável. Contudo, há mais de uma probabilidade de resposta aos questionamentos que surgem durante o processo, mostrando que outras direções poderiam ser tomadas ou ainda, que os limites estabelecidos no início do trajeto não estariam solidificados.

Em vista destes aspectos, outro fator importante sobressai: o movimento. Apoiados no raciocínio adotado por Lawson (2011), enfatizamos que o pensamento projetual é marcado por um ciclo de avanços, retrocessos e deslocamentos do pensamento. Consequentemente, sob esse fluxo cíclico e interativo, é pertinente deduzir que a coleta de informação é contínua, a retroalimentação das análises é constante e que, frequentemente, aparecem linhas paralelas de pensamento.

Desta forma, o pensamento projetual não pode ser entendido como um esquema fechado e linear de decisões, se o representássemos graficamente (FIGURA 1) se aproximaria mais de uma estrutura multidimensional, cíclica, com um núcleo focal que se amplia ao receber novas informações e se afunila ao conectar essas informações para decidir o próximo passo em direção à resposta, compondo um sistema aberto de interações possíveis.

Fig. 1. Estrutura esquemática do pensamento projetual.

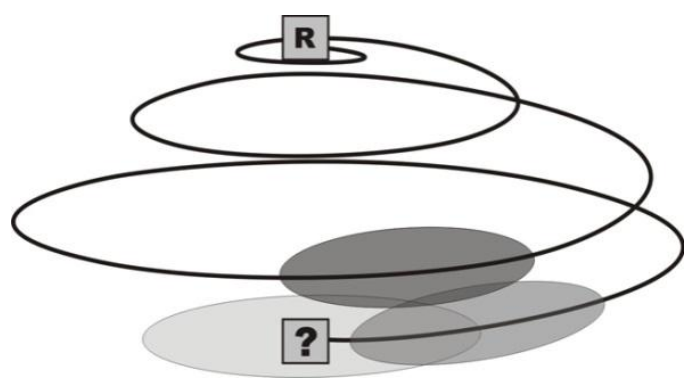

Fonte: Sanches (2010)

Apesar das limitações de uma representação esquemática bidimensional, a imagem anterior se destina a ilustrar a percepção de um trajeto de raciocínio que pode se abrir a novas possibilidades indefinidamente, ou promover novos movimentos do pensar. Dessa maneira, constrói-se um sistema de interações, em que os sujeitos envolvidos tomam decisões continuadamente sobre o caminho a seguir, tendo que lidar 
com os recorrentes ciclos que encadeiam análises, sínteses e avaliações. (LAWSON, 2011).

Diante da constatação do dinamismo e da diversidade que caracterizam o projeto, é natural que se levantem conjecturas sobre como gerir tal processo. Nesta direção, se considerarmos a já citada multiplicidade da realidade contemporânea, visto que todo projeto de design se vincula às solicitações do contexto sociocultural, vislumbramos um panorama de raciocínios intrincados e multifacetados. Logo, parece pertinente deduzir que os problemas de design surgidos neste cenário devem receber um tratamento flexível e integrante, no qual as ações sejam interativas e passíveis de redirecionamentos, a partir da comunicabilidade de saberes. $\mathrm{Na}$ mesma linha de raciocínio, Hernandis (2012), Moraes (2010), Vassão (2010) e Cardoso (2012) avaliam que a complexidade do cenário atual demandam abordagens sistêmicas para o design, argumentando que as metodologias para organizar a multiplicidade de variáveis precisam ser igualmente interativas e dinâmicas.

Realçamos também que, para a organização do raciocínio projetual, Cipiniuk e Portinari (2006) afirmam que, dependendo do problema tratado e do corpo teórico a que ele se relaciona, podem ser empregadas duas tipologias metodológicas: os métodos de tipo caixa preta ou os de caixa transparente. No primeiro, importa conhecer e controlar as entradas e informações coletadas para que se obtenham resultados esperados e, ao contrário, nos de caixa transparente, o objetivo não é dominar a relação de entradas e saídas, mas sim compreender os processos da mente e como se estabelecem as conexões entre conteúdos, trazendo à luz o processo de criação e a sistematização da conexão das variáveis que interferem na solução de problemas detectados no contexto sociocultural.

Neste ponto, o leitor pode se perguntar se articulamos ideias sobre o modo de pensar do designer ou sobre o modo de gerenciar as atividades do projeto. $\mathrm{O}$ fato é que os dois estão atrelados e muitas vezes se fundem nas análises, já que investigar o trajeto do raciocínio também implica em entender sobre que condutas ele avança. Por isso, não nos interessa isolar um ou outro, mas realçar que o desenvolvimento do raciocínio projetual na formação passa pela conexão entre o pensar e o agir sistemicamente.

Cabe um esclarecimento sobre o pensamento sistêmico, definido por Capra (1988) como aquele que é consciente das inter-relações e interdependências dos fenômenos da vida, sejam eles biológicos, físicos, culturais ou sociais. De acordo com o 
autor, embora seja possível particularizar os elementos dos sistemas, a natureza do todo sempre será diferente do que a simples soma das partes e, portanto, pode-se dizer que as inter-relações entre os elementos gerarão sempre dinamismo e fluidez.

Este modo de pensar se mostra bastante adequado à condução de um projeto de design. Cardoso (2012) afirma que a prática do pensamento sistêmico no design é a capacidade de avaliar os acontecimentos ao seu redor e as suas possíveis implicações, a fim de criar uma solução integrada que possa contemplar as expectativas de todas as partes envolvidas.

Sob esta perspectiva, os procedimentos realizados no transcurso do projeto adquirem também uma natureza sistêmica, em que se observa um conjunto de elementos inter-relacionados e interdependentes, no qual o comportamento de um afeta e depende do estado geral do conjunto e as vinculações são estabelecidas em prol de um objetivo comum. Porém, no caso do design, as inter-relações não estão restritas exclusivamente a um conjunto fechado de componentes, visto que as ações projetuais estão em comunicação constante com o ambiente em que se desenvolvem. Logo, a visão sistêmica do projeto sugere que o processo origina um sistema de interações aberto, no qual se percebe "subsistemas que, por sua vez, podem ser sistemas abertos e que, portanto, interagem entre si, com o sistema ao qual pertencem e com o ambiente" (MISOCZKY, 2003, p.4)

Hernandis e Iribarren (2000) exaltam essa comunicabilidade contínua, quando analisam o projeto como um sistema interdependente, propondo um modelo para a análise de problemas de design. O modelo, denominado "Diseño Concurrente", apresenta uma estrutura que situa o contexto gerador da demanda (problema) como um sistema amplo e aberto ("Sistema Exterior”), o qual compreende, alimenta e influencia o "Sistema em Estudo" (ou "Sistema Produto"), sendo este último o sistema que se ocupa da gestão das variáveis de projeto, transformando-as em diretrizes para possíveis soluções. Por sua vez, o "Sistema em Estudo" abrange "Subsistemas Fundamentais" de inter-relações, os quais se ocupam de integrar as variáveis em quesitos funcionais, ergonômicos e formais.

Da mesma forma, destacamos Santos (2012) que, ao analisar o papel das metodologias no ensino de projeto, propõe o método aberto MD3E, o qual fomenta a 
postura proativa do aluno e a flexibilidade para desdobramentos sistemáticos do trajeto projetual.

A partir dos estudos supracitados, assumimos que o projeto de design constitui um sistema permeável que se transforma constantemente na interação com o entorno. Logo, é pertinente pressupor que solicita competência integradora e habilidade de gestão, para perceber e conectar os elementos que participam do sistema. Fica claro então, que para auxiliar os estudantes de Design de Moda na construção do raciocínio projetual, é fundamental delinear que tipo de elementos e procedimentos costumam caracterizar o projeto nesta área e as aptidões específicas que são necessárias para projetar o vestuário de moda.

Neste sentido, iniciamos pela síntese apresentada por Sanches (2011), embasada pelas recomendações de Redig (2006), acerca das categorias de ações que envolvem o ato de projetar no design, a saber:

A) ATENDER- refere-se aos procedimentos que focam a observação e identificação das demandas a serem acatadas pelo projeto. B) ABRANGER- ressalta a conduta sistêmica que o processo deve manter, tratando da conexão entre os inúmeros fatores e sujeitos envolvidos. C) INOVAR- enfatiza o pensamento criativo na busca de inovação na definição das funções do produto, estimulando procedimentos que valorizam a expressão e a experimentação para evolução das ideias em um ciclo contínuo de observação e análise. D) DEPURAR- destaca os procedimentos de avaliação e síntese para o refinamento e otimização do ciclo de uso do produto. E) SEDIMENTAR- sobre a postura crítica que o designer precisa ter, propondo uma atuação que associe o uso dos recursos e o ciclo de vida do produto da melhor maneira possível.

Sanches (2011) identifica, a partir de suas pesquisas sobre as práticas do design de moda em âmbito acadêmico, que existem quatro grandes conjuntos de procedimentos comumente utilizados: A) procedimentos para contextualizar e sintetizar parâmetros projetuais (atender-abranger); B) procedimentos para gerar e experimentar possibilidades de conexão dos parâmetros, propondo soluções (inovar-depurar); C) procedimentos para avaliar e refinar a eficácia das possibilidades geradas (depurarsedimentar); D) procedimentos para consolidar a viabilidade técnico-construtiva das propostas (sedimentar-implantar). 
Embora pareça uma organização bastante lógica, a mesma autora ressalta que tais conjuntos não formam uma cadeia linear e tampouco ocorrem isoladamente, habitualmente incorrendo em sucessivos ciclos de retroalimentação. Diante dessas descrições tão maleáveis, não é tarefa fácil organizar diretrizes para guiar os primeiros passos dos estudantes, mesmo que o nosso propósito seja que, no decorrer da formação, eles se apropriem da conduta projetual e tomem decisões autônomas sobre os métodos que usam.

Pelo exposto, iniciamos esta tarefa ponderando que, se o designer se dedica a projetar interfaces entre os seres humanos e o seu entorno, o processo projetual emerge das solicitações do contexto e finaliza submergindo outra vez na mesma realidade que o definiu, transformando-a e, possivelmente, influenciando novas solicitações. Assim, é pertinente deduzir que devemos conhecer que tipo de informações definem as variáveis projetuais e também as interações geradas pelo artefato projetado.

Perante tal raciocínio, nos dedicamos, primeiramente, à identificação dos agentes relacionados ao desenvolvimento dos artefatos (tangíveis ou intangíveis) de moda, a partir dos quais detectamos as categorias de informações que influenciam a definição de objetivos do projeto e, por conseguinte, da síntese do conceito gerador, conforme ilustrado na Figura 2.

Para esclarecimento do leitor, adotamos o termo "conceito gerador", à semelhança de Sanches (2008), destacando que projetos de vestuário de moda geralmente englobam a concepção de vários artefatos em concomitância, os quais se vinculam por uma mesma ideia central. Essa essência partilhada irá gerar os princípios funcionais e de estilo do conjunto de artefatos projetados, respeitando a imagem da marca e as metas comerciais da empresa que propõe os novos produtos e/ou serviços. A ideia expressa pelo conceito gerador deverá ser decodificada em elementos compositivos de configuração, guiando todo o processo projetual. 
Fig. 2. Fluxo de informações entre os agentes influenciadores do projeto de Design de Moda.

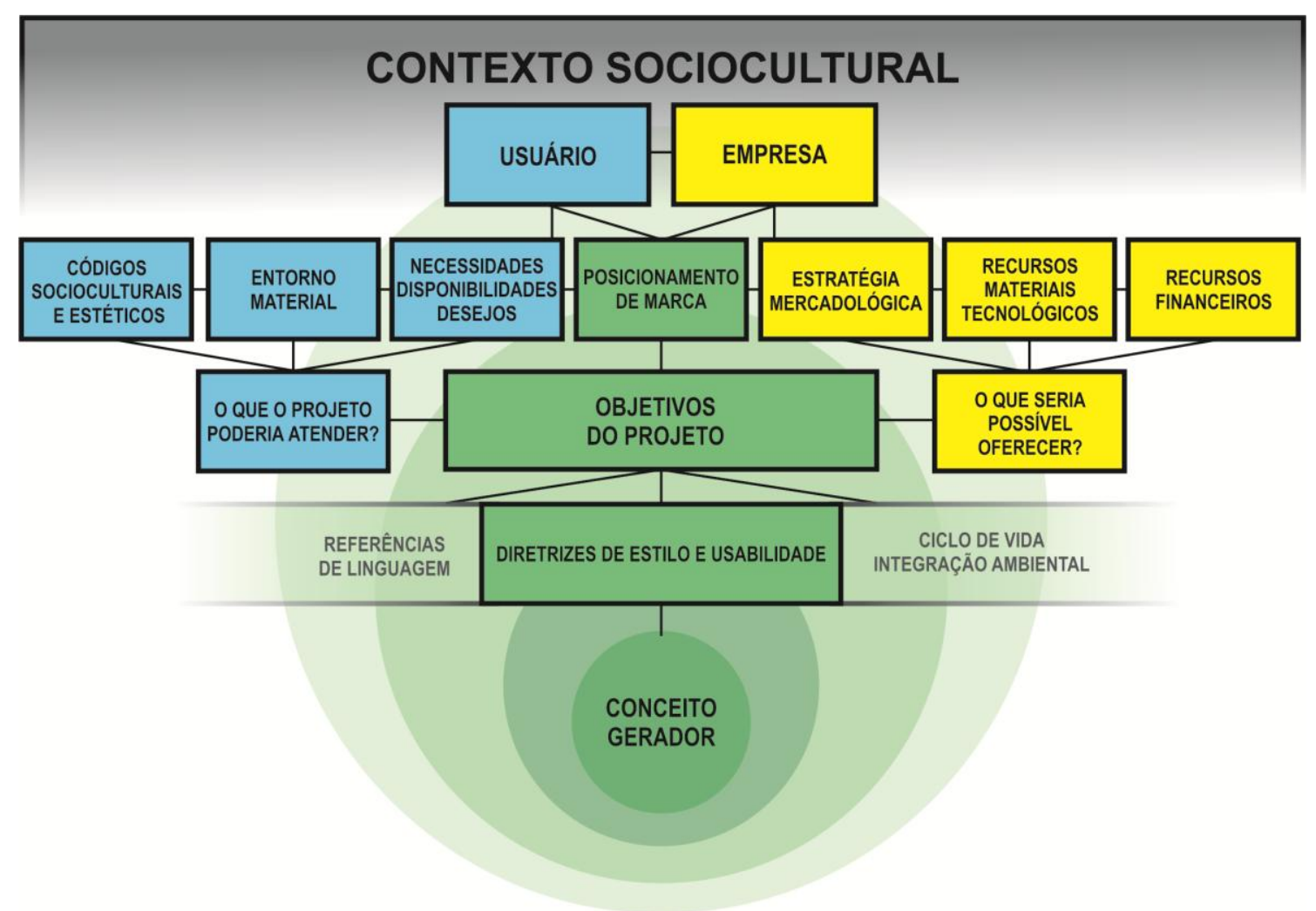

Fonte: elaborado pelos autores adaptado de Sanches (2011)

Qualquer comunicação apresentada de forma esquemática pode não transmitir a riqueza ou o dinamismo dos mecanismos ali explicados, porém a apreensão por esses meios é direta e coesa, facilitando a percepção da estrutura geral do sistema de relações. Desta forma, apresentamos o fluxo de relações que origina informações relevantes para o planejamento de diretrizes, a síntese de critérios e restrições projetuais. Com a mesma cautela, instruímos que a separação em caixas e cores tem fins didáticos, apenas para evidenciar as categorias de informações primordiais e representar, por meio de uma cor secundária (verde) que mescla duas primárias (azul e amarelo), a interação dos universos usuário e corporativo, imersos em um universo sociocultural (cinza), interagindo continuamente. 
Igualmente, é preciso compreender os termos usuário e empresa de forma ampliada. Logo, "usuário" compreende a noção de sujeito(s) a quem se destina o artefato projetado, uma entidade que integra componentes físicos, psíquicos e sociais; "empresa" engloba a noção de entidade que produz e insere artefatos de moda (tangíveis ou intangíveis) no ambiente humano.

Cabe enfatizar que o projeto pedagógico do curso estudado prioriza a integração entre as atividades acadêmicas e o contexto produtivo/mercadológico, tendo em vista que Londrina está localizada em um importante pólo industrial do vestuário. Por esse motivo, no transcorrer do curso, o ambiente controlado da academia é permeado pelo fluxo de variantes do contexto externo, instituindo uma interface com o âmbito corporativo, por meio de parcerias com empresas nos projetos integradores e experimentais. Logo, é fundamental apreender mercado e produção em nossas análises.

Ressalvamos ainda que os conjuntos de informações apontados frequentemente estão sobrepostos ou interpolados, cabendo aos envolvidos no projeto o desafio de decodificá-los como variáveis de entrada no sistema projetual. Para reforçar que esta representação não descreve um sistema linear e fechado, as camadas circulares ao fundo lembram que o fluxo de informações é cíclico e que ideias incipientes de solução costumam surgir antes da definição clara dos objetivos, podendo aguçar a percepção da demanda projetual estudada. Nesse rumo Lawson (2011) confirma que os limites entre o problema e a solução do projeto são difusos, visto que muitas vezes não se pode compreender o problema sem uma primeira visualização de formas de resolvê-lo.

Embora as situações projetuais sejam extremamente variadas e cada profissional possa encontrar seu modo particular de gerenciá-las, os estudiosos do design pontuam procedimentos recorrentes nestas situações e modos de pensar compartilhados entre aqueles que se dedicam a projetar. Nesta direção, Lawson (2011) cita as colocações de Nigel Cross, sobre os procedimentos que os projetistas costumam realizar e as capacidades que os mesmos exigem, para classificar as habilidades do projetar em categorias de pensamento, as quais explicamos resumidamente a seguir:

A) FORMULAR- reúne as habilidades para encontrar e expressar os problemas, entendê-los e examiná-los. B) REPRESENTAR- envolve as habilidades de exteriorizar as ideias e pensamentos, para comunicar, organizar ou rearranjar informações, conceitos incipientes, problemas e objetivos projetuais. C) MOVIMENTAR-SE- refere-se à 
capacidade de realizar os sucessivos deslocamentos de pensamento para conectar ideias, interpretá-las e desenvolvê-las. D) AVALIAR- refere-se à capacidade para avaliar e decidir, à competência para julgar alternativas com base em critérios e tomar decisões sobre que rumo seguir. E) REFLETIR- habilidades ligadas ao esforço consciente para manter o projeto no rumo dos objetivos, menciona a supervisão da própria conduta no decorrer do trajeto projetual.

O mesmo autor destaca a relevância da prática reflexiva, diferenciando dois tipos de reflexão: refletir em ação e refletir sobre a ação. O primeiro combina as habilidades e atividades envolvidas em "formular", "movimentar-se" e "avaliar", quando o designer reflete continuadamente sobre o entendimento do problema e a validade das soluções que vão surgindo. Já o segundo processo, envolve um afastamento mental e uma visão panorâmica, para perguntar se o processo caminha bem ou deve ser levado a outra direção, ampliando o aprendizado do projetista sobre os meios que utiliza para gerir o processo projetual.

Considerando essa conduta reflexiva, é inevitável não pensar que a construção de uma abordagem sistêmica para a formação de designers deverá estimular uma postura participativa do estudante. Isto significa incluí-lo nas decisões sobre os métodos que utilizará para gerir a próprio trajeto projetual e estimulá-lo a perceber o foco das suas ações, deliberando sobre que ferramenta metodológica será mais adequada. Diante dessa constatação, verificamos que o raciocínio sistêmico na formação de designers requer inevitavelmente um "projeto do próprio processo de projeto", ou seja, carrega um olhar de Metaprojeto (MORAES, 2010) ou Metadesign (VASSÃO, 2010).

Finalmente, depois de desvendar os pontos cruciais do desenvolvimento projetual e o fluxo de variáveis envolvidas no design de moda, faz sentido argumentar que o percurso projetual é também um processo de gestão de informação e conhecimento, no qual reside uma essência de pesquisa aplicada. Neste sentido, encontraremos, a cada situação projetual, a necessidade de desvendar universos, identificar códigos vigentes, formular objetivos, sintetizar conceitos, experimentar propostas e comunicar soluções. Sobre isso conectaremos algumas contribuições no tópico discussão.

À luz dos conceitos citados anteriormente e das observações de muitos anos de docência em disciplinas de metodologia projetual, concordamos que o enfoque 
sistêmico é o caminho natural para a gestão de projeto no design de moda e deve ser estimulado como forma de construção do conhecimento autônomo e do raciocínio reflexivo. Sendo assim, a disciplina de Metodologia do Projeto transforma-se em um “espaço de reflexão em torno do fazer" (COELHO, 2006, p. 40). Sob este direcionamento, apoiamos que os estudantes sejam estimulados a decidir sobre as ferramentas metodológicas que usarão em cada fase do projeto, dependendo do foco de ação da fase em questão e do repertório individual.

Contudo, isto não significa lançá-los à própria sorte; é preciso orientá-los na construção do repertório e na capacidade de identificar que tipo de ação é necessária para decifrar uma circunstância projetual, com o cuidado de não tomar um ou outro método como modelo hegemônico. Reafirmamos que "os problemas de projeto nem sempre apresentam as mesmas exigências e, portanto, os mesmos métodos de solução." (BAXTER, 1998, p. 06).

Em resumo, dadas as características de incerteza, diversidade e movimento constante que permeiam a prática projetual, evidencia-se um processo não linear, de variáveis que se influenciam mutuamente e formam um sistema permeável. Desta perspectiva, acreditamos que o papel da metodologia (incluindo técnicas, métodos ou qualquer "ferramenta" que auxilie o andamento do processo) no design é sistematizar processos com um nível de flexibilidade que permita ajustá-lo à diversidade das situações projetuais.

\subsection{Aprender a Projetar}

É inevitável que ao estudar o ensino/aprendizagem, nas esferas da formação profissional, nos acerque a ideia de pontuar as habilidades e competências necessárias para o profissional em questão. Valente (2002) comenta que, embora a ideia de competências e habilidades permeie a maioria dos discursos sócio-educacionais atuais, esta abordagem retoma princípios construídos há muito tempo. A esse respeito, a autora destaca a Escola Nova, tendência educacional que colocou em prática a teoria de Dewey, datada do final do século XIX; a Aprendizagem para o Domínio, proposta por Bloom nos anos 50; o Construtivismo de Jean Piaget, o qual já influenciava as propostas educacionais no início do século XX. 
Estas teorias demarcam a noção de que a aprendizagem é construída por meio de interações constantes entre o sujeito que aprende, o objeto do ensino e o ambiente externo, sendo diferenciadas pelo foco dado a cada um dos elementos presentes no processo de ensino. Dependendo da abordagem e das estratégias adotadas pelo professor, a preponderância de um elemento sobre outro pode exercer função de dominação ou de inter-relação, privilegiando desde a construção de competências particulares do sujeito, até a transformação social do ambiente pelo processo de aprendizagem. (VALENTE, 2002).

A mesma autora conclui que, entre os estudiosos da área educacional, não há consenso sobre os conceitos de habilidade e competência, os quais se mostram ora diferenciados e ora inseparáveis. Por outro lado, alguns teóricos do design citam as habilidades e competências que a formação profissional do designer deve desenvolver, mas não se ocupam de diferenciar limites. Da mesma forma, assumimos que o interessante para esta pesquisa é enumerar certas aptidões importantes a serem desenvolvidas no transcurso da formação, sem a inquietação de categorizá-las nestes termos, visto que, certamente estaremos tratando de capacidades integradas. Neste sentido, a pesquisa exploratória aqui descrita se ocupa de identificar tais aptidões. Para isso, destacaremos as bases teóricas que apoiam as nossas reflexões acerca das abordagens pedagógicas adequadas ao tratamento sistêmico do projeto no Design de Moda.

Seguindo as definições propostas por Pozo (1998), as atuais teorias cognitivas de aprendizagem se dividem em duas grandes correntes: A) Condutismo, baseado na conduta humana e nas ideias associacionistas de estímulo-resposta. B) Cognitivismo, baseado nas atividades cognitivas do sujeito. Segundo o autor, embora existam divergências de pensamento entre as correntes, ambas se apoiam na ideia de que o processo de construção do conhecimento se inicia pela formação de conceitos.

Os conceitos, de acordo com as definições expostas por Fialho (2001), exercem o papel de unidades categorizadoras, que permitem que se fale de um mesmo objeto por diferentes níveis de generalidade. Ao categorizar, o sujeito estará classificando os elementos ao seu redor, associando-os em classes e fazendo com que exista um sentido às palavras e expressões que ele utiliza. 
É importante ressaltar que o termo "conceito gerador", utilizado no tópico anterior, embora contemple essa ideia categorizadora, vinculando elementos que partilham uma mesma classe, não representa a amplitude do vocábulo quando usado neste tópico. No âmbito do ensino/aprendizagem de projeto, entendemos que a síntese de conceitos, para o desenvolvimento do raciocínio projetual, atua como delimitador dos estímulos nos processos de contextualização, definição dos parâmetros projetuais, avaliação e consolidação de ideias.

Neste sentido, enquanto a abordagem condutista afirma que a aprendizagem de conceitos deve-se aos potenciais excitatórios e inibitórios de um determinado estímulo, a corrente cognitivista relaciona a atividade de aprender à capacidade do sujeito em significar um estímulo e combiná-lo às suas experiências e conteúdos adquiridos anteriormente, para solucionar as novas questões envolvidas no processo de aprendizagem.

Transportando estas relações ao contexto do design, pode-se dizer que ele se aproxima do processo de aprendizagem cognitivista, uma vez que é considerado por Mozota (2011) como uma atividade interdisciplinar e coordenativa, em que os conceitos devem ser adquiridos, combinados e transformados. Isto pressupõe que o aprendiz desta atividade seja capaz de conectar variáveis de forma a encontrar a melhor solução na integração dos fatores delimitadores do projeto.

Minguet (1998) e Pozo (1998) dividem a escola cognitivista em quatro grandes correntes teóricas que, embora tenham se desenvolvido a partir de diferentes objetivos de estudo, colocam os aspectos cognitivos individuais como centro de suas pesquisas. As teorias da percepção, proposta pela psicologia da Gestalt; da equilibração, desenvolvida por Piaget; da recuperação, estudada por Vygotsky; e da aprendizagem significativa, conduzida por Ausubel, formam, segundo os autores, os pilares estruturais do Cognitivismo.

Ao estudar tais teorias, Miotto (2014) analisa que enquanto a Gestalt investiga a função ocupada pela percepção do todo e suas partes no processo de construção do conhecimento, a teoria piagetiana afirma que para conhecer um fato ou objeto é necessário agir sobre ele, modificando o seu significado e entendendo como ele é construído. Enquanto os pensadores destas correntes entendem o desenvolvimento como algo que ocorre isoladamente, através da ativação das estruturas cognitivas do 
indivíduo, a teoria de Vygotsky é a primeira a considerar as instruções como parte do processo de construção do conhecimento. Assim, o instrutor passa a ocupar papel fundamental durante a aprendizagem. É, neste sentido, que Ausubel propõe que, durante o processo de aprendizagem, além do conteúdo abordado pelo orientador, os conhecimentos prévios do aluno sejam valorizados, contribuindo na construção das estruturas e dos esquemas mentais, possibilitando uma aprendizagem prazerosa e eficaz.

De modo generalizado, entendemos que estas bases teóricas poderiam ser utilizadas como estratégias de ensino em diferentes níveis do processo projetual de design, pois definem objetos particulares de pesquisa, comuns à atividade projetual. Porém, ao considerar os interesses de investigação aqui delimitados, concordamos com Pelizzari, et. al (2002), quando afirmam que a aprendizagem se torna significativa quando o novo conteúdo se incorpora às estruturas do conhecimento do aluno, adquirindo significado a partir das relações estabelecidas com seu conhecimento prévio.

Assim, ao retomar que o processo do pensamento de design insere a gestão de informações e conhecimentos, e considerando que aprender, de acordo com Mueller (2001), implica na organização e integração do conhecimento à estrutura cognitiva do indivíduo, uma vez que as novas ideias apenas são aprendidas e retidas quando os conceitos relevantes estão adequadamente claros e disponíveis, inferimos que as bases da teoria da aprendizagem significativa, considerada o quarto pilar da escola cognitivista, torna-se a melhor estratégia pedagógica a ser adotada no desenvolvimento do pensamento sistêmico para projetar.

Sob esta ótica, toda situação de aprendizagem exige um esforço, por parte do aluno, em organizar os conteúdos aprendidos com seus conhecimentos anteriores, fazendo com que haja uma resposta aos novos estímulos. Ao realizar estas conexões, o aluno constrói sua capacidade integrativa, sendo capaz de interpretar, gerenciar e entender a essência dos elementos que compõem as variáveis do projeto, de acordo com as referências já estabelecidas em sua estrutura cognitiva.

Analisando o contexto estudado e a estrutura curricular do curso de Design de Moda da UEL, organizamos, de acordo com os conteúdos abordados em cada série, como deveria ocorrer a evolução das aptidões individuais (tabela 1) e o processo de aprendizagem dos alunos (figura 3), em busca de um ambiente educacional que introduza os conceitos e estratégias didáticas propostas pela teoria da aprendizagem 
significativa. Deste modo, a tabela 1 apresenta a sequência construtiva da formação do pensamento projetual proposta pelo curso.

Tabela 1. Evolução das aptidões esperadas no trajeto formativo no Curso de Design de Moda da UEL.

\begin{tabular}{|c|c|c|c|c|}
\hline & $1^{\mathrm{a}}$ SÉRIE & $2^{a}$ SÉRIE & $3^{a}$ SÉRIE & $4^{a}$ SÉRIE \\
\hline $\begin{array}{l}\text { APTIDÕES } \\
\text { AMEJADAS } \\
\text { EM CADA } \\
\text { SÉRIE }\end{array}$ & $\begin{array}{l}\text { O aluno será } \\
\text { conduzido à } \\
\text { construção de } \\
\text { repertório básico, } \\
\text { associando os } \\
\text { conhecimentos e } \\
\text { conteúdos abordados } \\
\text { sobre as técnicas de } \\
\text { criatividade à prática } \\
\text { projetual. }\end{array}$ & $\begin{array}{l}\text { O aluno será } \\
\text { conduzido à } \\
\text { construção de } \\
\text { repertório } \\
\text { intermediário, } \\
\text { associando os } \\
\text { conhecimentos } \\
\text { adquiridos na } \\
\text { primeira série com } \\
\text { conteúdos sobre } \\
\text { público-alvo e } \\
\text { conceito de marca à } \\
\text { prática projetual. }\end{array}$ & $\begin{array}{l}\text { O aluno será } \\
\text { conduzido à } \\
\text { ampliação do } \\
\text { repertório anterior, } \\
\text { interatuando com } \\
\text { cenários produtivos e } \\
\text { mercadológicos, para } \\
\text { promover a } \\
\text { associação dos } \\
\text { conhecimentos de } \\
\text { gestão e } \\
\text { sustentabilidade à } \\
\text { prática projetual. }\end{array}$ & $\begin{array}{l}\text { Por meio das } \\
\text { experiências e } \\
\text { aprendizado dos anos } \\
\text { anteriores, o aluno } \\
\text { deverá ser capaz de } \\
\text { realizar um projeto } \\
\text { de alta } \\
\text { complexidade, } \\
\text { gerindo, de modo } \\
\text { autônomo, a } \\
\text { interação entre a } \\
\text { investigação } \\
\text { científica, a prática } \\
\text { projetual e a } \\
\text { produção material. }\end{array}$ \\
\hline
\end{tabular}

Fonte: elaborado pelos autores com base em Sanches e Hatadani (2014)

Ao analisar o exposto na tabela anterior, embasados pela experiência didática adquirida ao longo dos anos de docência no ambiente estudado, verificamos que, desde o ingresso no curso, o aluno é conduzido por aportes teóricos durante a exposição de novos conteúdos, mas a fixação dos conceitos apenas se dá após a realização de tarefas que permitem aplicá-los à pratica projetual. Neste sentido, observando os tipos de aprendizagem detectados no decorrer do processo formativo e os conteúdos específicos de cada série, na figura 3 demonstramos como os assuntos deveriam ser abordados para melhor organização do processo de construção do conhecimento. 
Fig. 3. Organização do conhecimento abordado durante a formação do aluno do curso de Design de Moda da UEL.

\begin{tabular}{|c|c|c|c|}
\hline $\begin{array}{l}\text { Aprendizagem } \\
\text { significativa } \\
\left.\text { ( } \text { (a }^{\mathrm{a}} \text { série }\right)\end{array}$ & $\begin{array}{c}\text { Análise } \\
\text { mercadológica }\end{array}$ & $\begin{array}{c}\text { Metaprojeto, gestão } \\
\text { do processo de } \\
\text { design }\end{array}$ & $\begin{array}{l}\text { Obtenção de } \\
\text { resultados } \\
\text { intuitivamente, visão } \\
\text { sistêmica }\end{array}$ \\
\hline ( $2^{\mathrm{a}}$ série $)$ & $\begin{array}{c}\text { Trocas de } \\
\text { experiências em sala } \\
\text { de aula }\end{array}$ & $\begin{array}{l}\text { Laboratório de } \\
\text { experimentação de } \\
\text { possibilidades de } \\
\text { projeto }\end{array}$ & $\begin{array}{l}\text { Identificação de } \\
\text { necessidades / } \\
\text { problemas }\end{array}$ \\
\hline \multirow[t]{2}{*}{$\begin{array}{l}\text { Aprendizagem por } \\
\text { repetição } \\
\left(1^{\mathrm{a}} \text { série }\right)\end{array}$} & $\begin{array}{l}\text { Conceitos e teorias } \\
\text { sobre design, } \\
\text { métodos e técnicas }\end{array}$ & $\begin{array}{c}\text { Exercícios de } \\
\text { técnicas de } \\
\text { modelagem, costura } \\
\text { e representação }\end{array}$ & $\begin{array}{l}\text { Experimentações } \\
\text { tridimensionais, } \\
\text { análise de tarefa, } \\
\text { construção de } \\
\text { superficies }\end{array}$ \\
\hline & $\begin{array}{l}\text { Aprendizagem por } \\
\text { recepção }\end{array}$ & $\begin{array}{l}\text { Aprendizagem por } \\
\text { descobrimento } \\
\text { guiado }\end{array}$ & $\begin{array}{l}\text { Aprendizagem por } \\
\text { descobrimento } \\
\text { autônomo }\end{array}$ \\
\hline
\end{tabular}

Fonte: elaborado pelos autores adaptado de Miotto (2014).

Ponderando que para alcançar resultados significativos durante a aprendizagem, o aluno deve possuir um repertório de conteúdos previamente adquiridos e fixados em sua estrutura cognitiva, concluímos que isto só ocorre por meio da repetição de processos técnicos e conceituais. Martínez-Mut e Garfella (1999) complementam este raciocínio ao afirmarem que conforme as novas informações vão sendo fixadas na estrutura cognitiva, a repetição clássica é abandonada e dá lugar à compreensão total das novas aprendizagens.

No entanto, para que isto ocorra, são necessárias duas condições: a primeira diz respeito à predisposição do aprendiz em aprender significativamente, já que compreender novos processos exige esforço; a segunda relaciona-se ao material utilizado durante a instrução do aprendiz, que deve ser potencialmente significativo, lógica e psicologicamente, ou seja, seus elementos - conceitos, figuras, esquemas devem estar organizados em estruturas lógicas de acordo com a natureza dos conteúdos, 
para que cada aprendiz imprima sua leitura sobre eles, e construa os significados psicológicos da nova informação. (POZO, 1998; PELIZZARI, et. al, 2002)

Bzuneck (1991) afirma que, da mesma forma que os esquemas conceituais fazem parte da organização da estrutura cognitiva, também podem ser utilizados como ferramenta no processo de ensino. De um modo geral, os esquemas funcionam basicamente como roteiros, que podem ser ativados todas as vezes que uma nova informação ou problema for apresentado ao indivíduo, fazendo com que ele interprete as situações de acordo com os roteiros já existentes em sua memória. Devido à individualidade dos sujeitos, os esquemas operam como uma espécie de teoria particular inacabada que será complementada a cada nova aprendizagem.

No que concerne à aplicação dos esquemas conceituais, em forma de ferramentas facilitadoras durante o processo de ensino, Martínez-Mut e Garfella (1999) afirmam que eles têm por objetivo representar as relações significativas entre os conceitos, na forma de proposições. Para que eles possam ser introduzidos na estrutura ensino-aprendizagem de forma eficaz, é necessário que o aprendiz seja capaz de: entender a natureza e as relações existentes entre os conceitos analisados; extrair significados específicos do referencial teórico utilizado na transmissão do conteúdo; ser capaz de organizar a hierarquia de um mapa conceitual, segundo as estruturas definidas como importantes na resolução da atividade; expressá-lo por meio de representações gráficas que demonstrem as ligações entre os conceitos.

\footnotetext{
Nos casos de resolução de problemas, o uso de esquemas possibilitará que se levem em conta determinados aspectos do problema, além de certos princípios ou regras pertinentes. Em outras palavras, os esquemas relevantes, como roteiros, possibilitam que se capte a estrutura do problema e que, a seguir, se proceda com soluções quantitativas e qualitativas adequadas. (BZUNECK, 1991, p. 143-144)
}

Esta alegação pode ser diretamente relacionada à atividade do design, que se propõe a resolver problemas cotidianos, por meio do projeto de soluções criativas. Assim, durante o processo projetual, o designer recorrerá aos seus esquemas cognitivos para capturar a essência do problema estudado e definir quais as suas possíveis soluções. Porém, isto só será realizado de forma intuitiva a medida em que ele já tiver formado, em sua estrutura cognitiva, a hierarquia das ações que constituem o raciocínio projetual. Portanto, considerando as discussões realizadas até aqui e o ambiente acadêmico como espaço destinado à construção do conhecimento, cremos que, em 
primeira instancia, cabe aos professores das disciplinas de projeto a inserção dos recursos iniciais, organizando os conteúdos e metodologias disponíveis, durante a tentativa de estimular o aluno ao pensamento sistêmico. Contudo, esse papel de condutor deve ser exercido com flexibilidade, para que o processo permita o crescimento autônomo do aluno, no qual o papel do professor seja o de facilitador da aprendizagem e incentivador da descoberta dos possíveis recursos.

\section{Resultados e Discussões}

Considerando que o alicerce teórico indicou a relevância de enumerar direcionadores para a gestão de variáveis no trajeto projetual, iniciamos tal tarefa pela identificação das categorias essenciais de informação que permeiam o design de vestuário de moda. Neste sentido, foram detectados os agentes influenciadores da delimitação do problema e objetivos projetuais. Assim, foi possível perceber o fluxo de informações que gera os inputs (variáveis de entrada) do projeto. No entanto, ao estudar que tipo de respostas se espera do design de moda, identificando que classes de vínculo as interfaces vestíveis estabelecem na experiência com o artefato, foi possível estender as análises aos outputs (variáveis de saída) do projeto. Esta visão panorâmica proporcionou a confirmação de que o projeto de vestuário deve integrar quesitos de adaptação física, expressão individual e, principalmente, representação social, marcando a relevância dos fatores intangíveis no design de moda (Quadro 1).

Quadro 1. Níveis de Interação na Experiência de Uso do Vestuário de Moda.

\begin{tabular}{|c|c|c|}
\hline Principais Parâmetros Elencados & Categoria de Experiência & Indicadores \\
\hline Segurança (materiais e acessórios) & \multirow{3}{*}{$\begin{array}{l}\text { EXPERIÊNCIA EXTRA- } \\
\text { CORPORAL }\end{array}$} & \multirow{4}{*}{ FUNCIONALIDADE } \\
\hline Peso e Resistência (materiais) & & \\
\hline Facilidade de Manutenção & & \\
\hline Proteção Corporal & \multirow{4}{*}{$\begin{array}{c}\text { EXPERIÊNCIA SENSÓRIA } \\
\text { Adaptação física } \\
\text { Vestibilidade }\end{array}$} & \\
\hline Liberdade de Movimentos & & \multirow{5}{*}{ USABILIDADE } \\
\hline Conforto Tátil & & \\
\hline Conforto Térmico & & \\
\hline Facilidade de Manuseio & \multirow{6}{*}{$\begin{array}{c}\text { EXPERIÊNCIA COGNITIVA } \\
\text { Expressão Individual } \\
\text { Representação Social }\end{array}$} & \\
\hline Praticidade & & \\
\hline Versatilidade & & \multirow{4}{*}{ PRAZER } \\
\hline Atratividade & & \\
\hline Identificação pessoal/social & & \\
\hline Simbolismo & & \\
\hline
\end{tabular}


Fonte: Sanches (2015)

O conhecimento das categorias de variáveis do design de moda permitiu identificar o foco da busca de informações, promovendo a classificação de grupos de informação que podem guiar a pesquisa aplicada e servir de critério para a prática reflexiva. Tais conexões promoveram a síntese de um esquema conceitual que pode referendar as estratégias didáticas em sala de aula. A partir das classificações de Sanches (2011), Redig (2006) e Lawson (2011), representamos no Quadro 2 um paralelo entre as ações de pesquisa aplicada e as categorias de pensamento, as quais estão vinculadas às aptidões fundamentais a serem exercitadas na formação do designer de moda.

Quadro 2. Conexão entre as ações de pesquisa e as categorias do pensamento.

\begin{tabular}{|c|c|c|c|}
\hline PESQUISAR... & FOCO DAS AÇÕES & & $\begin{array}{l}\text { CATEGORIAS DE } \\
\text { PENSAMENTO }\end{array}$ \\
\hline $\begin{array}{l}\text { Universo Usuário } \\
\text { necessidades/desejos/disponibilidades }\end{array}$ & \multirow{3}{*}{$\begin{array}{l}\text { Contextualizar } \\
\text { especificar diretrizes }\end{array}$} & \multirow{3}{*}{ 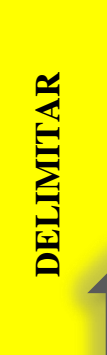 } & \multirow{3}{*}{ FORMULAR } \\
\hline $\begin{array}{l}\text { Universo Corporativo-Produtivo } \\
\text { expectativas/estratégias/recursos }\end{array}$ & & & \\
\hline $\begin{array}{l}\text { Códigos socioculturais e estéticos } \\
\text { (conteúdo de moda) }\end{array}$ & & & \\
\hline $\begin{array}{l}\text { Parâmetros de utilidade, } \\
\text { adaptação e percepção }\end{array}$ & \multirow{2}{*}{$\begin{array}{l}\text { Conceituar } \\
\text { Experimentar } \\
\text { possibilidades de } \\
\text { conexão }\end{array}$} & \multirow{2}{*}{$\underset{\frac{1}{4}}{\frac{1}{6}}$} & \multirow{2}{*}{$\begin{array}{l}\text { MOVIMENTAR-SE } \\
\text { REPRESENTAR }\end{array}$} \\
\hline $\begin{array}{l}\text { Conceitos de configuração } \\
\text { experiência tangível e intangível }\end{array}$ & & & \\
\hline $\begin{array}{l}\text { Detalhes de configuração } \\
\text { Experimentação das interfaces } \\
\text { tangíveis e intangíveis } \\
\text { Integração de comunicações técnicas }\end{array}$ & $\begin{array}{l}\text { Depurar } \\
\text { avaliar eficácia das } \\
\text { interações } \\
\text { Consolidar } \\
\text { testar, refinar implantar }\end{array}$ & 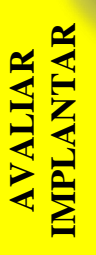 & $\begin{array}{l}\text { AVALIAR } \\
\text { REFLETIR }\end{array}$ \\
\hline
\end{tabular}

Fonte: elaborado pelos autores com base na pesquisa realizada

O sistema de relações ilustrado anteriormente confirmou a necessidade de aptidões que possibilitem gerir o processo de forma integrada, flexível e reflexiva. Neste sentido, o estudo averiguou que a gestão do processo projetual é guiada pelo mote do 
pensamento sistêmico, indicando que posturas metodológicas que estimulam a reflexão e gestão autônoma, como Diseño Concurrente, MD3E, Metadesign ou Metaprojeto, são as mais indicadas.

Em relação às posturas pedagógicas que favoreçam este raciocínio sistêmico, concluímos que a "aprendizagem significativa" pode vincular-se estreitamente ao design, visto que esta corrente estimula o papel de pesquisador de novos conceitos e possibilidades para associá-los ao repertório individual. Por outro lado, o uso de esquemas conceituais, possibilita a visualização do escopo do projeto em visão panorâmica, auxiliando o aluno na definição das próprias estratégias e na conexão real das variáveis do projeto. Isso sugere a importância das ferramentas que exploram o pensamento visual, como forma de expressar e sintetizar relações, permitindo que o estudante mapeie de forma consciente o problema, defina o escopo do projeto e direcione a busca por informação.

Destarte, o Modelo de Diseño Concurrente já emprega uma organização que valoriza o pensamento visual para interagir os subsistemas que se integram na configuração do produto. Por isso, foi adotado como modelo sistêmico para a gestão da delimitação projetual nas experimentações de campo, as quais já estão em andamento e serão tema de outra reflexão.

Finalmente, sintetizamos três construtos fundamentais para o desenvolvimentos da capacidade projetiva no design moda: permeabilidade - projeto como sistema aberto; investigação reflexiva - projetar como pesquisa aplicada; reflexão integrativa - aprender sistemicamente.

\section{Considerações finais}

Diante do exposto, a pesquisa exploratória delineou caminhos mais claros para o propósito final da pesquisa de doutoramento, a qual estuda ferramentas metodológicas para a sintaxe formal do vestuário de moda, no âmbito da formação acadêmica. Neste sentido, acreditamos que a abordagem sistêmica, direcionada pela aprendizagem significativa, permitirá que os alunos tenham mais autonomia e reflexão ao gerir o próprio conhecimento, auxiliando na definição do conceito gerador e dos elementos compositivos para a sintaxe da configuração das interfaces projetadas. Por outro lado, sob a ótica da aprendizagem significativa, a postura proativa e investigativa pode ser 
estimulada, criando, entre os sujeitos envolvidos nas práticas educacionais de projeto, uma relação de alteridade.

Nossa familiaridade com o universo estudado propiciou a visão panorâmica do percurso acadêmico, isso favoreceu uma apreciação do raciocínio projetual em formação contínua e, consequentemente, a síntese de conceitos que não se resumem ao escopo de uma única unidade curricular. Portanto, é importante advertir que as abordagens adotadas implicam em atuações que não se restringem à disciplina de Metodologia de Projeto. Igualmente, a construção integrada do conhecimento será menos árdua se o projeto pedagógico do curso for concebido com essa intenção integradora, como é o caso do curso em estudo.

\section{Artigo recebido em Julho de 2015. Aprovado em Setembro de 2015 DOI:http://dx.doi.org/105965/1982615x08172016119}

\section{Referências}

BZUNECK, J. A. Conceito e funções dos esquemas cognitivos para a aprendizagem: implicações para o ensino. Semina: Ciências Sociais e Humanas, Londrina, v. 12, n. 3, p.142-145,1991. Disponível em:

<http://www.uel.br/revistas/uel/index.php/seminasoc/article/view/9280/7954>. Acesso em: 10 jun. 2013.

BAXTER, M. Projeto de Produto: guia prático para desenvolvimento de novos produtos. São Paulo: Edgard Blücher, 1998.

CAPRA, F. O ponto de mutação. 26. ed. São Paulo: Cultrix, 2006.

CARDOSO, R. Design para um mundo complexo. São Paulo: Cosac Naify, 2012. 264p.

CIPINIUK, A; PORTINARI, D. B. Sobre métodos de Design. In: COELHO, L.A. [org.], Design Método. Rio de Janeiro: Ed. PUC-Rio; Teresópolis: Novas Ideias, 2006. p. 17-38.

COELHO, L. A. Por uma Metodologia de Ideias. In: COELHO, L. A. L. (Org.). Design Método. Rio de Janeiro: Ed. PUC Rio. Teresópolis: Novas Ideias, 2006. v. 1, Cap. 2, p.39- 53 .

DIAS, A. C. ; GONTIJO, L. A. A interdisciplinaridade no Ensino do Design. Revista Design em Foco, v. III, n. 2, p. 49-66, 2006.

FIALHO, F. Ciências da Cognição. Florianópolis: Insular, 2001. 
HERNANDIS, B.; IRIBARREN, E. Diseño de Nuevos Productos: una perspectiva sistémica. Valencia: Universidad Politécnica de Valencia, 2000.

HERNANDIS, B. Diseño Concurrente. In: MARTINS, R. F.; LINDEN, J. C. S (organizadores). Pelos caminhos do design: metodologia de projeto. Londrina: EDUEL, 2012. p. 327-396.

LAWSON, B. Como arquitetos e designers pensam. São Paulo: Oficina de Textos, 2011.

MARTÍNEZ-MUT, B.; GARFELLA, P. A construção humana através da aprendizagem significativa: David Ausubel. In: MINGUET, P. A. [org.], A construção do conhecimento na educação. Porto Alegre: ArtMed, 1998. p. 127-148.

MINGUET, P. A. O construtivismo na educação. In: MINGUET, P. A. [org.], A construção do conhecimento na educação. Porto Alegre: ArtMed, 1998. p. 11-50.

MIOTTO, T. A. O ensino da metodologia projetual no desenvolvimento de produtos de moda: um estudo de caso na universidade estadual de londrina. 2014. $110 \mathrm{f}$. Dissertação (Mestrado) - Curso de Ppg em Design, Faculdade de Arquitetura Artes e Comunicação, Universidade Estadual Paulista Julio de Mesquisa Filho, Bauru, 2014.

MISOCZKY, M. A. Da abordagem de sistemas abertos à complexidade: algumas reflexões sobre seus limites para compreender processos de interação social. Cad. EBAPE.BR, vol.1, n.1, p.01-17, 2003. Disponível em:< http://www.lume.ufrgs.br/handle/10183/21303> Acesso em: 01 de lulho de 2014.

MORAES, D. D. Metaprojeto: o design do design. São Paulo: Blucher, 2010.

MOZOTA, B. Gestão do Design. São Paulo: Bookman Editora, 2010.

MÜELLER, A. O Processo de Aprendizagem: Uma abordagem da teoria significativa. Florianópolis: 2001. Disponível em:

<http://deps.ufsc.br/disciplinas/fialho/ergcog/trab_alunos/T2001A/Artigos/Alessandro Muller.zip>. Acesso em 02 mai. 2013.

PELIZZARI, A. et al. Teoria da aprendizagem significativa segundo Ausubel. Revista $P E C$, Curitiba, v. 2, n. 1, p.37-42, jun. 2002.

POZO, J. I. Teorias cognitivas da aprendizagem. Porto Alegre: Artes Médicas, 1998.

REDIG, J. Design é Metodologia: procedimentos próprios do dia-a-dia do designer. In: COELHO, L. A. L. (Org.). Design Método. Rio de Janeiro: Ed. PUC Rio; Teresópolis: Novas Ideias, 2006. v. 1, Cap. 12, p.169- 177.

SANCHES, M. C. F. Projetando moda: diretrizes para a concepção de produtos. In: PIRES, D. B. [org.], Design de Moda: olhares diversos. São Paulo: Estação Das Letras e Cores Editora, 2008. p. 289-301. 
SANCHES, M. C. F. Projeto integrador: uma reflexão para a evolução da sistematização de projeto no ensino de design de moda. Projetica, Londrina, v.1, n.1, 2010. Disponível em: <http://www.uel.br/revistas/uel/index.php/projetica/article/view/7707/6859>. Acesso em: 01 de jul.2015

SANCHES, M. Uma análise da delimitação projetual no design de moda. In: VI CIPED Congresso Internacional de Pesquisa em Design, 2011, Lisboa, Portugal. Anais... VI Ciped, Congresso Internacional de Pesquisa em Design, Lisboa: CIAUD, 2011. (CD$\mathrm{ROM})$.

SANCHES, M. C. F; HATADANI, P. S. A Prática Interdisciplinar como Diretriz do Projeto Pedagógico do Curso de Design de Moda da Universidade Estadual de Londrina. Projética Londrina, v.5,n.1, 2014. Disponível em:

<http://www.uel.br/revistas/uel/index.php/projetica/article/view/19051> Acesso em: 01 de dez.2014

SANCHES, M. C.; ORTUNO, B. H.; MARTINS, S. R. Fashion design: the project of the intangible. In: 3rd International Conference on Affective and Pleasurable Design, 2015, Las Vegas. AHFE 2015 Conference Proceedings. Las Vegas: Y. G. Ji and S. Choi, 2015.

SANTOS, F. A. MD3E (Método de Desdobramento em 3 Etapas): conceito de método aberto de projeto para a aplicação no ensino de design . In: MARTINS, R. F.; LINDEN, J. C. S (organizadores). Pelos caminhos do design: metodologia de projeto. Londrina: EDUEL, 2012. p. 151-172.

VALENTE, S. P. Parâmetros Curriculares e Avaliação nas Perspectivas do Estado e da Escola. 2002. Tese (Doutorado em Educação) - Universidade Estadual Paulista, Marília.

VASSÃO, C. A. Metadesign: ferramentas, estratégias e ética para a complexidade. São Paulo: Blucher, 2010. 